\title{
Linguistic Politeness in the Chinese Language and Culture
}

\author{
Horng-Yi Lee \\ Department of Modern Languages and Literatures, Whittier College, Whittier, CA, USA
}

\begin{abstract}
This paper aims to explore the cultural foundations of polite speech and analyze its usage and practice in modern Chinese. A language mirrors the culture it is associated with. Grounded in the Chinese tradition and the teachings of Confucianism, the emphasis on rites, propriety and humility led to the development of polite language from the early imperial time. Because of the absence of related syntactic features, Chinese linguistic politeness is predominantly manifested on the lexical level. A rich array of decorous terms and expressions has been evolved accordingly to express courtesy or respect either verbally or in formal writing. In general, the lexicon of politeness can be classified into four major categories, namely, honorifics, humble language, courteous speech, and euphemisms.
\end{abstract}

Index Terms - Chinese, politeness, honorifics, humble language, euphemisms, culture

\section{INTRODUCTION}

The presence of well-mannered citizens is an icon of a civilized society. To be polite is an attitude as well as a universal social norm. It is essential in maintaining good interpersonal relationship and a harmonious society. Being aware of politeness also plays a significant role in effective cross-cultural communication.

Politeness can be achieved by either verbal or non-verbal behaviors. In the United States, polite speech can be not asking embarrassing questions about one's personal life, or using courteous expressions to inform people before certain actions take place. Other than the linguistic practice, physical gestures also serve to convey politeness or deference to the receiver. For example, keeping proper personal space or holding the door for the person next to you to enter is viewed as mannerly in American culture. In Chinese or East Asian cultures, people bow to elders, superiors or others when appropriate in order to give respect or show appreciation; use both hands to receive business cards or presents from others to express gratitude and to display good manners; or bend over slightly while shaking hands with guests to extend welcome greetings.

From the perspective of sociology and sociolinguistics, politeness is associated with face (Goffman, 1955, 1967). Face, according to Goffman, is the positive image or impression you want to present in front of others in social interactions; and the image you want people to observe might vary depending on the context. Taking Goffman's theory as a foundation, Brown and Levinson (1978) further proposed a framework that politeness stems from the concept of positive and negative face with the goal to safeguard interpersonal relation and to avoid or minimize face-threatening activities. Positive face is the need for self-image to be accepted, appreciated and approved by others; while negative face is the desire to be free from intrusion or not to be imposed on by others which is based on the assumption that people respect each other's privacy. Accordingly, behaviors such as complimenting one's work or showing sympathy demonstrate positive politeness, respecting other people's desire for privacy and leaving them alone involves negative politeness.

Although Goffman did not disclose the source of face, it depicts certain aspects of the notion of face and face-work that exists in Chinese culture (Hu, 1944; Gu, 1990). Face, lian or mianzi in Chinese, is an intricate and abstract concept which does not have precise translation in English. It generally renders as one's "reputation", "prestige", "dignity", or "honor". Everyone wants to "have face" (you mianzi) in front of others. People act in accordance with propriety to "gain face" for themselves and to save or give "face" (gei mianzi) to honor others in social interaction. If one talks or behaves indecorously and embarrasses oneself or others in public, both parties then run the risk of "losing face" (diulian or mei mianzi ).

While it might be true in elucidating the instrumental drive or purpose of being polite from the Western viewpoint, the Face theory does not give the full picture of politeness in the Chinese language and culture. From the Chinese perspective, politeness is conceptualized and deeply rooted in its long tradition, and is a core substance of behavioral norms.

\section{Fundamentals of Politeness In THE Chinese Tradition}

Language plays a vital role in transmitting culture. The study of a language enables the learner to explore and appreciate the related culture. The famous Sapir and Whorf hypothesis (Whorf, 1956) suggested that the structure of a language determines the thought and perception of its speakers. On the other hand, it can be argued that language and 
culture are intercorrelated, that our thoughts shape cultural patterns which, in turn, have significant impact on the formation of language as well as the words people use or choose.

The concept of politeness in the Chinese tradition and its practice in the language primarily stem from two important teachings of the Confucian doctrine, namely $L i$ and humility.

\section{A. The Concept of $\mathrm{Li}$ 禮}

Confucianism has been the mainstream of Chinese philosophy since the Han dynasty (206 BC - AD 220). $L i$ 禮, one of the core values in the Confucian code of ethics, is a collective term and generally refers to "ritual", "propriety", "ceremonial", "etiquette", "protocol" or, in a broader sense, good manners or good conduct. Prior to the time of Confucius, a system of moral principles with protocol as its foundation was set up to regulate daily life. Later in the Eastern Zhou dynasty (770-221 BC), the era when Confucius was born (551-479 BC), the political power of the central government declined sharply and all the feudal vassals contended for the control of the empire. Resultantly the formalities and rites previously established collapsed. Vexed by the political and societal upheaval, Confucius advocated for and placed great emphasis on $L i$ with the aim of preserving good social order, stability and harmony.

In the Analects (論語 Lunyu), a book composed of texts on the teaching and thoughts of Confucius as well as dialogues between Confucius and his disciples, a number of its sections are devoted to the discussion of $L i$. For example:

(1) 不學禮, 無以立. (論語, 季氏 16.13)

If you do not study the rituals, your character cannot be established and there is no basis to gain a footing in society. (Analects, 16.13)

(2) 子曰: 克已復禮為仁. (論語, 顏淵 12.1)

Confucius said: “To subdue oneself and return to propriety is perfect virtue.” (Analects, 12.1)

(3) 子曰: 恭而無禮則勞, 慎而無禮則葱, 勇而無禮則亂, 直而無禮則絞. (論語, 泰伯 8.2)

Confucius said: "Deference not bounded by the rules of propriety becomes tiresomeness; carefulness without propriety becomes timidity; boldness not bounded by the rules of propriety becomes insubordination, straightforward and outspoken without propriety becomes rudeness and harshness." (Analects, 8.2)

(4) 子曰: 道之以政, 齊之以刑, 民免而無恥; 道之以德, 齊之以禮, 有恥且格. (論語, 為政 2.3)

Confucius said: "If people are led by government policies and laws, and are regulated by means of punishment, they will try to avoid the punishment but have no sense of honor or shame. If they are led by moral force and keep order by the rules of propriety, they will have a sense of shame, and will come to good" (Analects, 2.3)

The excerpts quoted above illustrate the importance of $L i$ in fulfilling self-cultivation and establishing social order. $L i$ functions to regulate and rectify social behavior. Being reverent, circumspect, brave and forthright are good character traits, but should be restrained by $L i$ to reach the principle of golden mean, a major canon of conduct in Confucianism. To subdue oneself and return to propriety enables a person to get a footing and cultivate oneself approaching the perfect virtue Ren 仁 (benevolence), the ultimate aim and the core thought of Confucian philosophy. With $\mathrm{Li}$, one would behave properly in any situation. Quotation (4) manifests the expectation or admonition to the ruling classes that social harmony can only be attained by moral suasion and by the teaching of rules of propriety to people, while law and punishment are served as the minimum supports. Undoubtedly, to establish an affluent society with courteous citizens (富而好禮 fu er hao li) should be the mission a government strives to achieve.

In addition to the Analects, another major resource on $\mathrm{Li}$ is the Book of Rites (禮記 Liji), one of the five classics of the Confucian canon. Composed of forty-nine chapters, it is a collection of texts describing social norms, rules of propriety and a variety of ceremonial rites of the Zhou dynasty (1046-221 BC). In the very first chapter Quli, it delineates the essence of $\mathrm{Li}$ :

(5) 道德仁義, 非禮不成, $[\ldots]$ 是以君子恭敬撙節退讓以明禮. (禮記, 曲禮, 上)

Virtue, benevolence, and righteousness cannot be fully carried out without the rules of propriety. [...] therefore, the superior man is respectful and reverent, assiduous in his duties and not going beyond them, retiring and yielding, thus illustrating the principle of propriety. (Book of Rites, Quli, part 1)

(6) 禮尚往來, 往而不來, 非禮也; 來而不往, 亦非禮也. 人有禮則安, 無禮則危. 故曰: 禮者不可不學也. (禮記, 曲 禮, 上)

What the rules of propriety value is that of reciprocity. If I give a gift and nothing comes in return, this is contrary to propriety; if the thing comes to me, and I give nothing in return, that is also contrary to propriety. If people observe the rules of propriety, they are in a condition of security; if they do not, they are in one of danger. Hence there is the saying "The rules of propriety should by no means be left unlearned." (Book of Rites, Quli, part 1)

$\mathrm{Li}$ is not only a conceptual framework but also requires putting into practice. Passages (5) and (6) highlight the importance of practicing $L i$ in the social life. The reciprocity of giving and repaying is an example of basic courtesy that illustrates the omnipresence of $L i$ in everyday life. $L i$ prescribes the appropriateness of social behaviors. People would live with peace of mind if rituals and etiquette are observed and followed, otherwise the society would be in commotion. Moreover, those who are “well-educated and achieve proper mannerism” (知書達禮 zhishu dali) always receive high praise and admiration. 


\section{B. The Notion of Humility}

Along with the concept of $L i$, humility is a distinct behavioral quality expected in social interaction. From the Western standpoint, humble and self-effacing behavior tends to be viewed as withdrawn or lacking self-confidence. While it might somewhat disguise one's true intention, humility or modesty is regarded as a virtue that has long been celebrated in the Chinese culture. Citation (7) from the Book of Rites clearly exemplifies the linkage between $\mathrm{Li}$, deference and humbleness, that politeness can be achieved by disparaging oneself and elevating the other. It hence established the foremost principle of courteous speech in Chinese.

(7) 夫禮者, 自卑而尊人 (禮記, 曲禮上)

$L i$ is seen in humbling one's self and giving honor to others. (Book of Rites, Quli, part 1)

(8) 子曰: 君子義以為質, 禮以行之, 孫以出之, 信以成之. (論語, 衛靈公 15.18)

Confucius said: "A true gentleman is one who takes righteousness as the foundation, acts according to the rules of propriety, brings it forth in humility, and accomplishes it with sincerity. (Analects, 15.18)

Citation (8) outlines in what manner a virtuous true gentleman should behave, which includes rules of propriety and humility. Chinese people are taught to be modest from early childhood and trust that modesty is a virtue. Aphorisms such as "complacency leads to failure, modesty brings benefit" (滿招損謙受益 man zhao sun, qian shou yi) and “a greedy and complacent person will be harmed, a humble person will be blessed” (貪滿者多損謙卑者多福 Tanman zhe duo sun, qianbei zhe duo fu), all advocate the merit of humbling oneself. Humbleness does not imply incompetence or lacking ambition, and a “modest gentleman” (謙謙君子 qianqian junzi) is always extolled in the Chinese society.

While Western cultures have different expectations, it is not surprising to witness Chinese people deny or make modest remarks in the first place when receiving compliments, as staying humble or being self-effacing is the golden rule in social interactions. The idea of denigrating or belittling oneself and elevating the other sets up a convention of polite speech in the Chinese language ever since early times, and the influence continues to exist in contemporary Chinese.

\section{LiNGUisTIC POLITENESS IN IMPERIAL TIMES}

Given that the traditional Chinese culture values and endorses propriety and humbleness, an extended and complex inventory of polite lexicon has been developed accordingly.

The time of Confucius was a period of turmoil and conflict. Because the established social system proved to be inadequate, Confucius laid stress on the role of $L i$ and its associated rituals and forms with the hope of restoring the social order and inner quality of people. As a matter of course, this appeal was reflected in the language people used, and words or expressions in response to such thoughts were to evolve.

By and large, the societal structure of imperial China followed a patriarchal-based hierarchical system. The social standings of rulers and subjects, nobles and commoners, parents and children, men and women, were reinforced. Specific terms of address were employed verbally or in writing to differentiate social status, superiority and inferiority, or seniority in age and generation. Respect and humble terms were used widely as a basic form of communication.

The late imperial vernacular narratives serve as good resources for exploring pre-modern polite terms of address ${ }^{1}$. For example, in officialdom, the person who holding a lower official post addressed the superior daren (lit. 'big person'; your honor) and referred to himself as xiaguan ('lowly official') or beizhi ('inferior post'). In the courtroom, commoners disparaged themselves as xiaoren ('small person'), xiaomin ('little fellow'), or caomin ('straw fellow') to designate themselves as worthless. In the house, servants addressed their master as laoye ('senior master') and female servants referred themselves as nubi ('slave maid'). In business, keguan ('guest official') was the polite term used by waiters to address clientele in a restaurant.

Starting from the First Emperor of the Qin dynasty (221-206 BC), zhen was the self-reference term exclusively used by the emperor, though it could be used by anyone before his time. However, although emperors had the utmost power and authority, they might humbly refer to themselves as guaren ('solitary person') or $g u$ ('lonely') to display humility and virtue. In a sense, the emperor was truly a "lonesome" man. The term weichen ('diminutive official') was the selfreference word used by officials in front of the emperor. In the last dynasty of Qing, nucai ('slave person') was a selfreference used by eunuchs, or by low-ranking officials when they were received by the emperor.

In the old times, the status of women was inferior to men. The concept that "female is subordinate to male" and "wife is subordinate to husband" was entrenched in the mind of common people. Despite the fact that the family structure of ancient China was once a matriarchal system, men were traditionally considered the heads of household. The subordinate status of women to men was developed progressively as Confucianism flourished, especially when the NeoConfucianism came into being in the Song dynasty (960-1279 AD). It promoted the idea of the division of labor between men's duties outside and women's duties at home, and encouraged feminine virtues, such as obedience, quietness, good manners, etc. The distinction of the social standing between husband and wife is revealed by examining the terms of address. For example, the wife of a government official addressed her husband dutifully as guanren

\footnotetext{
${ }^{1}$ Linguistic corpus for pre-modern Chinese, Center for Chinese Linguistics PKU, 北京大學中國語言學研究中心, 古代漢語資料庫, http://ccl.pku.edu.cn:8080/ccl_corpus/index.jsp
} 
('official person') or laoye ('old master'); and the wife might refer herself humbly as jianqie (lit. 'despised wife'; this worthless wife). The husband used self-derogatory expressions such as jiannei (lit. 'despised inside'; my humble wife) or zhuojing ('clumsy wife') to refer to his own wife when engaged in conversation with others.

In the wake of the end of imperial China in 1911 and the occurrence of the May Fourth Movement in 1919, a patriotic as well as an anti-tradition social movement led by the social elite, submissive or servile terms were banned and abandoned. These old terms, however, can still be heard in cinematic productions and television drama series when they are set in imperial times.

Although the examples presented above are fairly limited and represent merely a small portion of the entire inventory, they display the patterns of polite expressions of the old times. As it turns out, a large quantity of related expressions was preserved and has carried forward into present-day Chinese. An analysis of polite lexicon is presented in the following section.

\section{Linguistic Politeness In MODERn CHINESE}

Polite speech is an indispensable component in many languages, so as to maintain an agreeable atmosphere and foster good interpersonal connection. In terms of linguistic structure, it can be manifested on the syntactic, morphosyntactic, or lexical level. The choice of formal versus informal form of the second person pronoun to indicate politeness is a common feature in many Indo-European languages, such as sie/du in German, usted/tu in Spanish, or vous/tu in French. Modern English, instead of having an alternate second person pronoun, uses modal auxiliary verbs (would/could/should /may...) to convey civility. On the other hand, some Asian languages such as Japanese and Korean consist of relatively complex honorific system of speech; honorific morphemes are agglutinated to verbs, nouns, or pronouns to signify formality, intimacy, social standing or social context.

Chinese is a semantically-oriented language; it does not have schemes of conjugation or inflections. Grounded on the notion of "elevating the others" and "disparaging oneself", Chinese language has developed a rich inventory of lexicon pertaining to denoting politeness, respect, or decorum in formal speech or writing. In general, polite expressions in Chinese can be classified into the following four major categories: honorifics, humble language, courteous speech, and euphemisms.

\section{A. Honorifics}

The use of honorifics is the direct way of showing respect by elevating the standing of addressee or the referent in relation to the recipient. In English, although there are few honorifics (e.g. sir, ma'am), certain words are expected to be used at specific times; for instance, "Your Honor" in the courtroom, "Your Excellency" in diplomatic circles, "Your Highness" to certain royal persons, "Your Majesty" in the presence of a king or queen.

There is a Chinese saying: “One who respects others is constantly respected by them." (敬人者人恆敬之 jing ren zhe ren heng jing zhi, Mengzi 孟子, Lilou, part 2). To treat people with respect is reciprocal and it is believed that no one could complain about excessive politeness (禮多人不怪 Li duo ren bu guai).

Generally, the Chinese honorifics can be grouped into noun phrases and verbal phrases.

\section{Noun Phrases}

In lieu of the regular second person singular pronoun $n i$ (you), nin is the polite form in modern Chinese to address the recipient. It is interesting to note that people of Beijing are likely to use nin more often than people in other parts of China. In addition to the regular titles of taitai (Mrs.) and xiaojie (Miss), nüshi (lady) is the polite and respectful term to address females. To those with high social ranks, furen (Madame) is the proper word to be adopted on formal occasions, such as zhongtong furen ('Mrs. President', the First Lady). Gexia (Your Excellency) is usually used to address prominent political figures such as the president or diplomats in the circle of foreign affairs.

Adjectival morphemes such as gui 貴, ling 令, xian 賢, gao 高 are adopted as prefixes to form a majority of honorific compound words signifying "honorable", "esteemed", or "respectful".

The word gui 貴 itself has the meaning of "expensive" or "precious". It denotes "your distinguished" or "your honorable" when used as a polite prefix. Words with this morpheme generally appear on occasions dealing with formality such as in business or foreign affairs. Common expressions include: guiguo (your country), guiguo renmin (your country's people), guigongsi (your company), guixiao (your school), guifu (your residence), guichu (your place), guiti (your body), guikan (your magazine), guibao (your newspaper), guibin (VIP), guike (honored guest), etc. Gui jiazhang (dear parents) and gui zidi (your children) are the terms to be used in correspondence to parents from the school official.

As a social convention, Chinese people have an inclination to address each other by profession or job title in public or official situations, particularly the first time people meet. The interrogative phrase of "guixing?" ("your honorable family name?') serves the purpose of politely asking one's surname, so that all interlocutors in the conversation are able to address one another in a mannerly way, such as Li jingli (manager Li), Wang zhuren (director Wang), or Liu jiaoshou (professor Liu). The phrase "guigeng?" ('honorable age') is a polite request to ask one's age. When in an office setting, the receptionist may possibly ask the visitor “Nin you he guigan?" (lit. 'you have what honored business?'; what brings you here?) to identify the purpose of one's visit. At times, people might tease someone who is forgetful by saying 
"guiren duo wang shi" (lit. 'honored person far more forgets things'). It implies that this person, just like a high-ranking person, is apt to be forgetful because of so many things drawing the attention.

The morpheme ling 令 has a definition of "good" or "excellent" when functioning as an adjective. It serves as a major honorific prefix to form appellations in reference to the addressee's family members, denoting "your graceful". For example, lingzun is the courteous substitute for the regular phrase "ni fuqin" (your father). Other similar words include lingtang (your mother), linglang (your son), lingai (your daughter), lingxiong (your elder brother), lingjie (your elder sisiter), lingmei (your younger sister), lingdi (your younger brother), lingqin (your relative).

Xian 賢 (capable, talented, virtuous) is also a morpheme functioning as a prefix to construct appellative honorifics. However, it is generally used when addressing those who are junior in either age or generation than the speaker, and is said with a sense of praise and approval. For example, xiandi (you virtuous younger brother), xianmei (you virtuous younger sister), xiankunzhong (you and your brother) are the terms of address to those who are younger than the speaker. In this case, the use of $d i$ (younger brother) or mei (younger sister) suggests the intimacy between the speaker and addressee, though there is no blood relation between them. This linguistic characteristic demonstrates an important cultural phenomenon in that Chinese people have a preference for treating friends or acquaintances as family members. Hence, it is a general practice to address non-relatives with terms of kinship. Addressing others with kinship terms such as dage (elder brother), dajie (elder sister), ayi (aunt) or shushu (uncle) is acknowledged as a means of showing politeness in the Chinese society. This prefix xian may also be used, mostly in writing rather than face-to-face communication, to refer to one's own relatives other than immediate family members, such as xianxu for one's own son-in-law and xianzhi for one's nephew.

In contrast with xian, zun 尊 (honorable, esteemed) more often than not is used courteously to refer to one with senior status, such as zunjia (your esteemed self), zunweng (your esteemed father), zunzu (your esteemed grandfather), zun furen (your esteemed wife). However, the phrase "zunxing daming?" (lit. 'esteemed surname and big first name') is a polite and formal way to inquire one's full name, but is not limited to seniors. While being "old" implies negative connotation of useless or weak, "old" to some extent denotes experienced or knowledgeable. Elders are viewed as a source of wisdom and to respect the aged is a tradition in the Chinese culture. Thus, to address someone with a surname followed by lao t (old), such as "Zhang lao" or "Wang lao", is also regarded as expressing esteem.

Some honorific expressions other than appellative terms contain the morpheme gao 高 (high, tall). For instance, gaojian refers to "your esteemed opinion or advice"; using gaojiu ('high employment') in the question "zai nar gaojiu?" to ask where one works; using gaoshou ('high age') in the interrogative phrase "jinnian gaoshou?" to ask the age of elders; gaozu (lit. 'high feet') is the word in reference to one's brilliant students; gaoshou (lit. 'high hand') refers to someone who is an expert or a master in a certain field.

$F u$ 府 (mansion) is a word to name the residence of high officials or eminent figures, such as zhongtongfu (presidential hall). Fushang is the polite term referring to either "your house, your family" or to ask one's hometown as in the question "fushang nali?" (Where is your hometown?). The phrase of "daofu fuwu" ('go to your house to serve') can be found in flyers or advertisements to promote the offering of in-house service.

Emphasis on the family is a key aspect of Chinese culture and family plays a significant role in an individual's life. The Chinese language has evolved a complex system of kinship appellations as every family relation has a specific term. As mentioned earlier, this familial concept has been extended to the outside members in that people tend to address non-relatives with terms of family relation. For instance, children are taught to address parents' friends as ayi (aunt) for females, shushu/bobo (uncle) for males, or yeye (grandpa) and nainai (grandma) for seniors. This pattern of address may also be applied to those with whom we are not acquainted. For instance, a salesperson might address an older female customer as "ayi" (aunt) to show politeness. Although these titles of blood relation are not considered as honorifics, it is the act and attitude of showing respect or intimacy.

Other miscellaneous but commonly used polite expressions include words such as baojuan (lit. 'treasure family members'; your family members); baohao (lit. 'treasure store'; your shop or store), dazuo (lit. 'big work'; your writings or literary work). Xianjin (lit. 'first advanced'; predecessors) is the courteous word adopted when addressing those who are senior in age or standing to honor their experience or length of service.

Verbal Phrases

A number of honorific verbal compound words are composed of, but not limited to, morphemes such as gong 恭 (respectfully), jing 敬 (respectfully), feng 奉 (with respect), bai 拜 (to do obeisance; to pay respect to), or hui 惠 (kind, gracious). All these words deliver a connotation of respectfulness when the action to be modified is carried out.

Gongjing is a compound word with the meaning of "respectful." When these two morphemes gong and jing are used separately to constitute other verbs, "respectful", "reverent", and "deferential" are still the core meaning. Examples of honorific verbs with the morpheme gong 恭 are such as gonghou (to respectfully wait), gongying (to respectfully welcome), or gongzhu (to respectfully wish). Either gongqing or dunqing (to respectfully invite) can be used when extending an invitation to someone with respect or cordiality. Gongxi means "to congratulate" or "congratulations" and the idiom "gongxi facai" is a common greeting which is heard during the Chinese Lunar New Year period with the meaning of "congratulations and be prosperous." In terms of jing 敬, words in common use include jingcheng (to present with respect), jinggao (to respectfully inform), jinghe (to congratulate with respect), jinghou (to wait 
respectfully). The word jingzhu (to respectfully wish) is a conventional phrase appearing at the end of a letter, such as the expression "jingzhu jiankang" (I respectfully wish you good health). Another word in ordinary use is jingqing ('respectfully please') as in the phrase "jingqing guanglin" (your presence is cordially requested) which is a standard expression on an invitation.

Verbs with feng 奉 include fenghuan (to respectfully return), fengquan (May I venture to advise you to ...), fengsong or fengzeng (to give away as a gift with respect). The word fengpei (to keep you company) is usually used in expressions "shu bu fengpei" (I am sorry to be unable to keep you company) and "fengpei daodi" (to accompany till the end). The word fenggao (to inform respectfully) is used to form the phrase "wu ke fenggao" (I have nothing to tell you; I have no comment).

The morpheme bai 拜 means "to do obeisance; to bow" which composes some verbs relating to paying a courtesy visit; for instance, baifang and baiwang are used for ordinary visits whereas baihui and baiye indicate formal visits in officialdom. When asking for help or a favor from others, one would use baituo (to entrust). Baidu (to read with respect) is the word to use as in the phrase "baidu dazuo" (respectfully peruse your work) when referring to reading someone's writing or publication.

Huici (to bestow graciously) or huishi (to kindly instruct) are compound verbs formed with the morpheme hui 惠 (kind, gracious). The word huigu (to kindly patronize my business) is typically used in the idiom of "mingxie huigu" (my gratitude to your patron) found in a shop or store. The word huicun (to kindly keep) is generally written along with autograph on the back of a photograph or on the inner page of a book in the hope that the gift can be kept as a souvenir by the recipient.

Additionally, there are many other terms of protocol used exclusively in formal letters, correspondence, or official documents. Given that the format of this kind of writing style has been simplified nowadays, most of these intricate terms seem obsolete and only those who acquire good training in traditional document writing could understand and use them in an appropriate manner.

\section{B. Humble Language}

Many appellative honorifics have counterparts in the humble form. As discussed in the previous section, being modest is a valued behavioral norm in the Chinese culture and consequently humble language is a distinctive feature in Chinese. Compared with honorifics, humble speech is the opposite way to show politeness or deference by lowering the status of one's self or the referent. The basic principle of humble language is self-depreciatory and belittling of oneself. Although the distinction between inferiority and superiority has practically been discarded in contemporary Chinese, the element of seniority is still observed.

Instead of using the regular first person pronoun wo (I), the speaker may use a humble term at the speaker's own discretion to refer to him/herself either verbally or in writing. The choice of a proper self-depreciatory term depends on the relative personal relationship with the addressee. In front of the senior generation, wanbei ('later-generation') or wansheng ('the later-born one') can be adopted to refer to oneself. Typically, a self-humbling term would not be applied when addressing one's social equals or same generation. Yet, zaixia (lit. 'be lower'; beneath you) is an alternative when it is appropriate, as in the polite and modest phrase "zaixia bucai" when humbly referring to oneself without talent or capability. At times the terms yuxiong ('foolish elder brother') or yudi ('foolish younger brother') may be used among males to refer to oneself in formal writing when addressing a friend of the same generation, since it is not uncommon that intimate friends treat each other as brothers. When presenting one's own opinion, zhuojian ('my poor opinion'), qianjian ('my shallow view') or yujian ('my stupid opinion') are the appropriate words to use. When mentioning one's own publication, one would humbly refer to it by the word of zhuozuo ('my poor writings').

In contrast to the honorific prefix ling 令, either jia家 (house, family, home) or she 舍 (house) are used as selfdepreciatory prefixes when one's own family members are mentioned. Examples are such as: jiafu (my father), jiamu (my mother), jiajie (my elder sister), jiaxiong (my elder brother), shemei (my younger sister), shedi (my younger brother). Different words are also used to refer to other family members such as one's husband, wife, or children; for instance, waizi ('the outside person') for "my husband"; neizi or neiren ('the inside person') for "my wife"; xiaoer ('little son') or quanzi (lit. 'dog son') for "my son”; and xiaonü ('little daughter') for "my daughter”. The morpheme she 舍 forms compound words referring to one's own residence such as hanshe ('cold and shabby house') and shexia (lit. 'house down'), which are in contrast with the honorific word fushang (lit. 'mansion up').

The morpheme $b i$ 敉, with the meaning of "worn-out, broken, tattered", is a self-depreciatory prefix denoting "my" or "our" in contrast to the honorific morpheme gui 貴. For example: biguo (my country) versus guiguo, bigongsi (my company) versus guigongsi, bixiao (my school) versus guixiao. In the previous section, the courteous way of asking one's surname is guixing, whereas bixing is the humble way to respond or introduce one's own surname, such as "bixing Li" (my 'humble' surname is Li).

Other than these compound words, there are some useful and frequently heard self-effacing phrases or idioms. It is a common practice and social convention that the response to a compliment or ovation received is "bugandang" (I don't deserve it), "guojiang" (you overpraise me), or an informal colloquial phrase "nali, nali" (lit. 'where, where'; you flatter me). When a person is asked or urged to perform impromptu in the presence of the public, one would humbly say "xianchou" (lit, 'to show ugliness') to indicate what he or she will present is of poor quality. "Paozhuan yinyu" (lit. "to 
throw a brick in order to get a piece of jade in return') is a humble expression that compares oneself or one's good deeds to a worthless brick and hope others as precious jade may follow or more help would be anticipated. The idiom "xiao quanma zhilao" (lit. 'to offer the labor of a dog or a horse') likens oneself to a loyal dog or horse to express one's loyalty when working for someone. It is similar to another phrase "jin mainbo zhili" (lit. 'to exhaust soft-thin strength') that one would do one's best to serve even with feeble strength or limited power.

Although the use of humble language may seem excessive at times, it does not imply subordination or inferiority, nor does it involve self-criticism.

\section{Courteous Speech}

The use of courteous expressions is to be perceived as well-bred and less abrasive or intrusive. People exchange polite expressions on either formal or informal occasions to show good manners, self-discipline, or self-cultivation, as well as to maintain harmonious human relationships. In addition to the general courteous expressions such as "thank you", "sorry", "excuse me", "please", "welcome", "may I ask..." and so forth, there are many other phrases to be used subject to the context. The following are some examples.

When people first meet at a social event, they would exchange greetings by saying "xinghui” (lit. 'lucky meet', my pleasure to meet you), "jiuyang" (lit. 'long admired'; I have admired you for a long time), or "qing zhijiao" ("please give advice') when presenting a business card. If one needs to leave in the middle of a gathering, one would say "shipei" (lit. 'lose company') to excuse oneself for not being able to keep you company. "Xinling" (lit. 'heart accept') is the word to appreciate the offer of service or a gift while declining it.

When inviting guests to have a meal at home, the host might say "mei shenme cai" (there is not much food) despite plentiful dishes on the table. To show hospitality, the host would urge the guest to eat more by saying "duochi yidian, biekeqi" (eat more, don't stand on ceremony). If one needs to leave early during the meal, "manyong" ('slowly eat') is the phrase to tell the rest to take the time to enjoy the meal. In order to show politeness, it is a general practice that the host walks guests to the main gate when seeing them off. In this case, the guest may say "qing liubu" ("please keep your step') to tell the host do not need to accompany further. In reply, the host would say "manzou" ('slowly walk') which functions the same as "drive safely" in English.

There are other courteous expressions used in everyday life. Tuofu (lit. 'by your fortunate') is a thankful expression in reply to being congratulated on a success or a narrow escape, for instance, that it is a result of the other person's blessing. Laojia (lit. 'to labor you') or "buhao yisi" (to feel embarrassed) are grateful expressions when one feels sorry to trouble someone to do something. Shangguang (lit. 'give light') means to honor one with one's gracious presence at a social event, as in the sentence "ganxie ninde shangguang" (thank you for your presence). The phrase "jingbei feizhuo" ('respectfully prepare little food and wine'), a standard expression always shown on a banquet invitation, is a combination of an honorific verb jingbei (respectfully prepare) and a humble noun feizhuo (a meager feast).

\section{Euphemisms}

Every culture has its taboos or things forbidden or unacceptable, which should be avoided. For instance, it was an old custom in imperial China to avoid mentioning the names of emperors or ancestors either in speech or in writing so as to show respect to them. Likewise, in modern time there are situations where people try to avoid bringing discomfort or embarrassment to others by using tactful or elusive words to replace words with taboo.

The use of euphemistic language is a rhetorical tactic which offers indirect and less blunt expressions for something thought to be unpleasant or offensive. One good example of this is with reference to "death". "Death" is a sensitive issue lots of people do not want to face or talk about. In English, alternatives for "to die" could be "pass away", "deceased", "rest in peace", "breathe one's last breath", "meet one's end", or others. Similarly, instead of saying "si" (to die) directly, there are a number of euphemisms in Chinese denoting one's passing away. In addition to those commonly used words such as shishi ('pass the world'), qushi ('gone the world') and guoshi ('pass this world'), there are more refined words such as: lishi (leave this world) xieshi (decline this world), cishi (farewell to this world), bainian (lit. 'a hundred years'), zuogu ('to be ancient'), shouzhong ('life span ends'), xianshi ('to be immortal'), changmian ('long sleep'), wangsheng ('toward born'), guitian ('return to heaven'), sashou ('release hands'), anxi ('peacefully rest'), or jian yanwang ('to see the king of Hell, Yama'). Buddhist terms for the death of monks or nuns include yuanji ('complete silence'), zuohua ('sit and change'), guixi ('return to the west'), niepan (nirvana), etc. If a person dies in childhood or at childbirth, it is called yaozhe (lit. 'young bend'); if one dies for one's country, it is called juanqu ('donate body'); xunzhi ('die for post') is the term for when one dies on one's job; if a person is killed in action, zhenwang ('battlefield die') is the proper word. The phrase "zou le" ('is gone') is probably the most common and simple way to inform people of someone's death.

Chinese people adopt softer or ingratiating words to replace things related to death or a funeral. For example, instead of saying "mudi" ('tomb lot, grave lot'), fudi ('blessing lot') is a more pleasant word to use because it is considered bad luck and will bring misfortune if selling "mudi" instead of "fudi", especially to elders. Shoucai ("longevity material') is a substitute for guancai (coffin), and shouyi ('longevity clothes') is a suitable word for shroud. In the hospital, taipingjian ('peaceful room') is substituted for mortuary, and dati (lit. 'big body') is a less harsh word for shiti (corpse).

Compared with Western cultures, Chinese culture is relatively conservative and reserved. Thus, linguistic avoidance is undoubtedly applied to words relating to sexual affairs, given that it is a breach of morality or offends public decency 
to talk about sexual issues bluntly. For example, except for medical purposes, people use xiati ('lower body') to refer to sexual organs and use fangshi ('bedroom matter') or other subtle words when mentioning the sexual life between husband and wife. If an unmarried couple engages in sexual behavior, people would say "fasheng guanxi" ('relations happened'). Tongzhi ('comrade') is a contemporary euphemism for homosexuals or LGBTs in Chinese-speaking societies, and "duanxiu zhipi" (lit. 'broken sleeve inclination') is an idiom that depicts male homosexuality which is derived from a historical story in the Han dynasty.

Furthermore, one thing worth noting is that colors may signify specific connotations in contemporary Chinese. The color yellow (huangse) is associated with pornography, such as "huangse dianying" (pornographic movies), "huangse shukan" (pornographic books and periodicals) or "huangse xiaohua" (pornographic jokes). The color green is generally positive except that "a green hat" has a derogatory implication. When a man is said to be "wearing a green hat", it implies that his wife is having an extramarital affair.

\section{Linguistic Politeness In ChinA AFTER 1949}

After four years of civil war following the eight years of Japanese invasion, China split into two political bodies and the Chinese Communist Party took over the regime on the mainland in 1949. Led by the ideology of Marxism and ruled by the dictatorship of proletariat, one of the main missions of this so-called "New China" was to establish a new value system and social norms. A series of political campaigns and societal reforms were launched to denounce traditional culture, mainly the Confucian thoughts and ideals. During the decade-long notorious Cultural Revolution (1966-1976), the movement of destroying the "Four Olds", namely old thinking, old customs, old culture and old tradition, was executed by the Red Guards all over China. Moreover, the idea of "equality" advocated by the Communist party eliminated the boundary of long-standing hierarchical social class. Since everyone is theoretically with equal standing, excessive ceremony or politeness would be redundant and unnecessary. Consequently, the traditional norms of decorum and gracious speech were thus devastated since they were representatives of the old world, and were considered anachronistic as well as in contradiction to the ideology of communism.

One practice of anti-tradition was exemplified in the system of terms of address (Pan \& Kádár, 2011). Regardless of formal or informal, the standard title was replaced by a universal and unisex term of tongzhi ('comrade'), and the word airen ('lover') was adopted to refer to one's spouse in place of "wife" or "husband". What we think of as ordinary terms of address, such as taitai (Mrs.) and xiaojie (Miss), were prohibited because these were words used by the inferior to address the family members of the master in the old times, and thus viewed as a product of bourgeoisie and had pernicious influence on the people and society. On the other hand, the slogan of "women hold up half the sky" manifested the important role played by the female and did advance the social status of women.

Everyday polite expressions such as "please", "thank you", "sorry", "excuse me" were not practiced in regular social interactions. This lack of politeness could easily be perceived as rudeness from the perspective of outsiders. It is unfortunate that the time-honored Chinese morals and linguistic politeness were cast away as rubbish for several decades in mainland China. Nonetheless, they have been well-preserved in the Chinese communities outside the Mainland, mainly in Taiwan.

The Cultural Revolution was a catastrophic decade for China because of its tremendous detriment to the Chinese cultural heritage. It was not until China opened up their doors to the world in the 1980s, following the practice of the "Reform and Open-Up" policy, did they realize that it was pressing to educate their people to be "civilized" again by the "cultural renaissance" of the ethic codes of the Confucian teachings and their tradition of civility. However, due to unfamiliarity with the correct usage of polite terms, misuse of honorifics is unavoidable. People tend to use the honorific furen in reference to one's own wife, or use fushang to refer to one's own residence. Although inadvertent mistakes happen, it is encouraging to witness that propriety and polite speech have gradually been picked up and their use has come back into people's daily lives.

\section{CONCLUSION}

The present study examines the cultural foundations, primarily derived from the teachings of Confucianism, and provides, through examples, an overview of polite speech in modern Chinese at the lexical level. Compared with other languages, Chinese has developed a fairly complex lexical inventory with reference to expressing politeness and deference in formal discourse and writing. The complexity of linguistic politeness manifests the importance of propriety and protocol in Chinese society. This paper also gives a brief but comprehensive account of the development of polite speech from a historical perspective.

Language and culture are so closely correlated that what people think and believe will reflect in their language and, in turn, reveal aspects of their culture. China has a long tradition of putting emphasis on rites and decorum, and showing politeness and respect by elevating the other or disparaging one's self has been an ordinary linguistic practice in accordance with social expectation. Thus, honorifics and humble language account for the two major components which include appellative and non-appellative terms. Most appellative honorifics have their counterparts in the humble form, and verbal honorific expressions are regularly employed in formal verbal communication and correspondence. The use 
of polite language not only reveals self-cultivation and good breeding, but also demonstrates sophisticated linguistic competence.

Every language has its standards of polite speech. Knowing properly "what to say", "when to say" and "to whom to say" indicates an individual's linguistic and communicative competence. Improper usage may offend the addressee and expose the linguistic incompetence of the speaker. Although polite speech has been simplified and refined in presentday Chinese, it is still considered bewildering and perplexing to learners.

The learning of a foreign language cannot be separated from an understanding of the culture and the society in which the language developed and is being used. Acquiring the cultural knowledge of a language and being familiar with its polite speech are vital to successful intercultural communication. The study of Chinese polite speech not only provides an effective tool to advance one's linguistic capabilities, but also enables the learner to gain insights into the Chinese value system and traditions.

This paper presents a framework for functional analysis on linguistic politeness, but the scope of study is limited. More in-depth elaboration at both the lexical and discourse levels as well as comparative studies between Chinese and other languages are recommended for future research.

\section{REFERENCES}

[1] Brown, P. \& S.C. Levinson. (1987). Politeness: Some universals in language usage. Cambridge: Cambridge University Press.

[2] Goffman, E. (1955). On face-work: An analysis of ritual elements in social interaction. Psychiatry: Journal for the Study of Interpersonal Processes, 18, 213-231.

[3] Goffman, E. (1967). Interaction ritual: Essays in face-to-face behavior. Chicago, IL: Aldine Publishing Company.

[4] Gu, Y. (1990). Politeness phenomena in modern Chinese. Journal of Pragmatics, 14, 237-257.

[5] Gu, Y. (1992). Pragmatic politeness and culture. Foreign Language Teaching and Research, 4, 30-32.

[6] Hu, H. C. (1944). The Chinese concept of 'Face'. American Anthropologist, 46, 45-64.

[7] Kasper, G. (1990). Linguistic politeness: Current research issues. Journal of Pragmatics, 14, 193-218.

[8] Legge, J. (1994). The Four Books: English translation and notes. Taipei: Culture Book Co.

[9] Legge, J. (2013). Book of Rites (Li Ji): English-Chinese version. By Confucius, et al; edited by Dai Sheng (AD 80); translated by J. Legge. Beijing: Intercultural Press.

[10] Pan, Y. \& D. Z. Kádár. (2011). Historical vs. contemporary Chinese linguistic politeness. Journal of Pragmatics, 43, 15251539.

[11] Redmond, M.V. (2015). Face and politeness theories. English Technical Reports and White Papers. 2. http://lib.dr.iastate.edu/engl_reports/2 (accessed 4/5/2019).

[12] Whort, B. L. (1956). Language, thought, and reality: Selected writings of Benjamin Lee Whorf. J. B. Carroll (ed.), Cambridge: MIT Press.

[13] Yang, B. (1996). Lunyu Yizhu (Confucian analects with translation and annotation). Hong Kong: Zhonghua Books.

Horng-Yi Lee received her M.A. degree in Chinese literature, and Ph.D. in education from the University of Southern California with emphasis on second language pedagogy.

She is currently an associate professor in the department of Modern Languages and Literatures at Whittier College in California, USA. She teaches all levels of Chinese language, Chinese linguistics, Chinese poetry and pre-modern literature. Selected publications include Inquiry-Based Teaching in Second and Foreign Language Pedagogy (JLTR, 2014), Qualitative and Quantitative Changes in Modern Chinese Affixes (JCLTA, 2014). Her primary research interests are second language pedagogy as well as Chinese lexicon and morphology.

Dr. Lee has served on the editorial advisory board of McGraw-Hill Companies, Higher Education. 